\title{
Perception and Acceptance of Information Technology (IT) Enabled Farm Advisory Service by Farmers of Navalgund Taluka of Karnataka
}

\author{
N. Rajeshwari" and S. S. Dolli \\ Department of Agricultural Extension Education, College of Agriculture, \\ UAS, Dharwad, India \\ *Corresponding author
}

A B S T R A C T

\section{Keywords}

Perception and acceptance, Information technology enabled farm advisory services, Farmers

Article Info

Accepted:

15 December 2020 Available Online: 10 January 2021
The research study was conducted in Navalgund taluka of Dharwad district of Karnataka State during the year 2018-19 to know the perception and acceptance of IT enabled farm advisory service by farmers. Exploratory research design was used to conduct the study. Four hundred farmers from eight Gram Panchayats of Navalgund taluka who were beneficiaries of information technology (IT) enabled farm advisory services were the respondents of the study. The data was collected through a semi structured interview schedule. A scale was developed to measure the perception and acceptance of information technology (IT) enabled farm advisory services. The results revealed that 43.25 per cent of the farmers fell in the category of medium perception, 40.50 per cent of the respondents fell in the category of high perception and only 16.25 per cent of the respondents were in low category of perception about information technology enabled farm advisory services. Out of the 11 dimensions studied six dimensions had an index more than 70.00 per cent i.e., field applicability (83.35\%), accuracy (78.45\%), comprehensiveness of content $(75.13 \%)$, presentation of audio- visual content $(72.43 \%)$, solution for pest and disease $(71.01 \%)$ and agricultural input selection $(70.58 \%)$. On the contrary speed had perception index of only 39.36 per cent. Other four dimensions ranged between 40-60 per cent i.e., follow up support/ assistance $(59.10 \%)$, user friendly device $(55.06 \%)$, timeliness $(48.71$ $\%)$ and market assistance $(44.50 \%)$. The overall perception index was 63.43 per cent. With respect to distribution of farmers according to different dimensions of perception and acceptance.

\section{Introduction}

Agriculture supports 52 per cent of work force in India and is a prominent sector of Indian Economy. Research, extension and farmers efforts all have contributed significantly to increase in food production. It is projected that demand for food grains may touch 280 million tonnes by the year 2020-21. A growth rate of nearly 2 per cent per annum in food grain production is needed to meet this particular demand and a growth rate of 4 per cent per annum is needed in agriculture sector. India despite having the largest irrigated land and ranks second in terms of arable land but the yield of crops is only 20 
per cent 40 per cent of the world's best levels (Anonymous, 2000). One of the reasons for the wide gap is extension worker to farmer ratio resulting in low access to technical information. The gap is still widening may be because of faulty delivery of extension system. To support the above fact extent of adoption of improved agricultural practices developed by research institutions is found to be very low among farmers (Anonymous, 2018).

Agriculture was also facing challenges like non-expanding land, depleting soil and water resources adverse impact of climate change, rising cost of production, diminishing agriculture labour availability and farmers reduced interest in agriculture. To make farm information and technology transfer more effective, greater use was needed to be made of modern information and communication technology among researchers, extension personnel, farmers and other stakeholders. Further the agricultural extension required paradigm shift from top-down, blanket recommendation of technological packages, towards providing producers with the knowledge and understanding with which they solve their own location specific problems, (Saravanan, 2010). As a result in late 1990's the presence of information communication technology was felt in agriculture sector also to cope up with the gap between farmers and research institutes.

\section{Agriculture and information communication technology in India}

Some of studies of ICT have demonstrated their effectiveness in filling the information gap and increased adoption of improved technology. The e Sagu project, a personalized agricultural advisory framework was implemented in 2004-05 which aimed to develop a model for providing personalized agricultural advice to farmers for major crops such as paddy, cotton, maize, chilli, castor, red gram, ground-nut in Andhra Pradesh. Similarly Electronic Solutions for Agricultural Pests popularly known as e- SAP has been successfully built \& tested and deployed by University of Agricultural Sciences, Raichur in association with Tene agriculture solution pvt. ltd, Bangalore. eSAP is a novel ICT platform and dedicated field device capable of making two way exchange of information in real time It addresses the field problems related to insect pests, microbial diseases, nutritional deficiencies and weed problems. The platform can disseminate information built in various forms like videos, animations, images, text and audio. The government's "Digital India" project launched on $1^{\text {st }}$ July 2015 envisions empowering citizens with e-access to government services and livelihood related services, among others. The project has three core components, viz. digital infrastructure, digital services and digital literacy. The mobile phone is the preferred delivery medium with focus on $\mathrm{m}$ Governance and $\mathrm{m}$ Services. The $m$ Agriculture and $m$ Gram Bazar, out of the seven components covered under $\mathrm{m}$ Services, directly impact agricultural extension and marketing services (Anonymous, 2020).

\section{Comprehensive Agribusiness Extension System (CABES)}

Comprehensive Agribusiness Extension System (CABES) was designed and implemented on project mode during 2017-18 in rainfed and irrigated ecosystems. CABES was a business approach where the focus is not on any single aspect of production but on all aspects of agribusiness such as crop planning, input procurement, crop production, value addition and marketing. The extension services was designed in such a way that it took into account all the above 5 dimensions in an integrated fashion to provide inputs 
periodically in a user friendly way. A project was implemented with the partnership of University of Agricultural Sciences (UAS), Raichur, University of Agricultural Sciences (UAS), Dharwad and Indian Institute of Management (IIM, Bangaluru). The responsibility of scientists of the University and Krishi Vigyan Kendra was to provide content related to crop revenue models which is location specific, this included cultivation practices for major crops of that area along with e- SAP services. The Non-Governmental Organization (NGO) which had the responsibility of working at field level, recruited Raitha Mitras to work with farmers. NGOs collated information on each crop business from various sources such as Universities, Department and other commercial establishments to be fed into the tablets to be used by Raita Mitra. NGOs trained Raita Mitras to front end (village level) to facilitate technical transfer of information using tablets. Raita Mitras also collected information from farmers on the practices followed by them. At the village level, the NGOs took the help of local graduates/diploma holders or those who have training in agriculture as Raita Mitras to reach individual farmers. The main aim of piloting was to test the model. An attempt was made to provide comprehensive information on farm management on real time basis to improve adoption, productivity and profitability. Hence, the present study proposed to analyse the effectiveness of CABES an information technology enabled farm advisory service by studying the perception and acceptance of information technology (IT) enabled farm advisory service by farmers of Navalgund taluka of Karnataka

\section{Materials and Methods}

The present study was conducted in Navalgund taluk of Dharwad district of Karnataka. Navalgund falls under northern dry zone with a typical rabi dominated unimodal rainfall. Navalgund taluka was purposively selected because Comprehensive Agribusiness Extension Services (CABES) an Information Technology enabled farm advisory service was provided in 20 Gram Panchayats under digital Krishi Project of Department of Agriculture, Government of Karnataka. The registered farmers in the treatment Gram Panchayats were provided with all the information pertaining to agriculture and allied activities in order to improve the yield levels and profitability. The services were given in a project mode in Navalgund Taluk of Dharwad district and 200 farmers from each Gram Panchayat were registered for the advisory services in Navalgund taluka. Four hundred farmers who were registered under Comprehensive Agribusiness Extension Services (CABES) an IT enabled farm advisory service formed the sample for the present study. A scale was developed to measure the perception and acceptance of information technology (IT) enabled farm advisory services. The data was collected with the help of the scale developed for the study from 400 registered farmers.

\section{Results and Discussion}

\section{Perception and acceptance of farmers of information technology enabled farm advisory services}

The information presented in Table 1 indicates the perception and acceptance of information technology enabled farm advisory services by farmers. When we study the overall perception of farmers, results have revealed that 43.25 per cent of the farmers had medium perception about IT enabled farm advisory services, 40.50 per cent of the respondents had high perception about information technology enabled farm advisory services and only 16.25 per cent of the respondents had low perception about 
information technology enabled farm advisory services. The result presented in Table 1 indicated that almost equal percentage of farmers had medium level (43.25\%) and high level of perception (40.55 $\%$ ) about IT enabled services. Several theories were put forth to explain factors affecting users behaviour regarding adoption of end user technologies like mobile phones. Among these, Technology Acceptance Model (TAM) proposed by Davis (1989) was widely used, accepted and tested. Davis' model is based on the premise that attitudes affect intentions, which in turn leads to certain kind of behaviour. To explain user acceptance behaviour, Davis proposed two constructs; viz; "perceived usefulness" and "perceived ease of use". Both these variables represent the end users' belief in technology and can be used to predict their perception and attitude towards the technology and its ultimate acceptance Sahota and Kameshwari (2014).Based on the above premises it can be observed that more number of farmers had high level perception this was a personalized farm advisory service where real time information was given which could further be made available for analysis and reporting. As the farmers had registered for the services it was easily available to them through field facilitators i.e. Raitha Mitras and perceive it in a better way. The Raitha Mitras was able to explain to the farmers about farming practices with the help of photographs, videos, animation, graphs, charts etc which resulted in right perception of advices of IT enabled service to get information. The tool has eSAP services which has not only helped farmers to know the best management practices but also helped in identification and management of pests and disease. Maraddi et al., (2016) who conducted a similar study to know the perception of the stakeholders of e SAP dissemination tool and revealed that about half of the field facilitators belonged to high perception category $(45.95 \%)$, while
36.98 per cent of farmers were in medium category.

\section{Perception and acceptance index of farmers towards different dimensions of IT enabled farm advisory services}

It can be deciphered from table 2 that out of 11 dimensions selected, six dimensions had an index more than 70.00 per cent i.e., field applicability (83.35\%), accuracy (78.45\%), comprehensiveness of content (75.13\%), presentation of audio- visual content (72.43 $\%)$, solution for pest and disease $(71.01 \%)$ and agricultural input selection $(70.58 \%)$. On the contrary speed had perception index of only 39.36 per cent. Other four dimensions ranged between 40-60 per cent i.e., follow up support/ assistance (59.10\%), user friendly device (55.06\%), timeliness $(48.71 \%)$ and market assistance $(44.50 \%)$. The overall perception index was 63.43 per cent. The results from table 2 revealed that out of 11 dimensions selected six dimensions had an index more than 70.00 per cent that includes field applicability, accuracy, comprehensiveness of content, presentation of audio- visual content, solution for pest and disease and agricultural input selection. The Tablet where e-SAP was made available contained pictures, videos, graphs and illustrations from pre-sowing operations to harvesting. Seed treatment, weeding, irrigation, pest management, nutrients management, other crop-specific interventions for major crops of Navalgund like green gram, onion, cotton, chilli, chickpea, jowar, wheat, Electronic Solution for Agricultural Pests (e-SAP) was made in such a way that it was able to identify the incidence of pests and disease and provide suitable solution on the spot in printed form. This might be the reason for good perception. On the contrary speed of service had an index of only 39.36 per cent. With respect to other four dimensions ranged between 40-60 per 
cent that include follow up support/ assistance (59.19), user friendly device (55.06), timeliness (48.71) and market assistance (44.50). The overall perception index was 63.43 per cent which means that as the farmers are well exposed to the content of the tab, more number of farmers accepted and used the technologies because it is a personalized farm advisory services. It can be concluded that Raitha Mitras were successful in providing the need based information to the farmers. The overall perception index observed was above 60 per cent. The main problem faced by rural people is the broadband connectivity. It is also seen in the study that the broadband connectivity wass poor that affected the speed of receiving information, it implies that the connectivity in the villages need to be improved to make IT enabled service more effective. The farmers might have faced the problem of connectivity problem to get quick response. Sometimes real time communication was made between farmers and scientists through internet. It is here that the farmers faced the connectivity problems. Overall perception score indicated that 83.75 per cent of the farmers fall under the category of medium and high level of perception. Xiaola and Shaheen (2005) who conducted similar study on Knowledge Help Extension Technology (KHETI) which Information Communication Technology (ICT) based extension service with the help of field facilitators called munna made a significant impact on usefulness and adoption of ICT based farm advisory services.

Table.1 Perception and acceptance of farmers towards IT enabled farm advisory services

\begin{tabular}{|c|l|c|c|}
\hline SI No & \multicolumn{1}{|c|}{ Perception } & Frequency & per cent \\
\hline $\mathbf{1}$ & Low $(<59.06)$ & 65 & 16.25 \\
\hline $\mathbf{2}$ & Medium $(59.06-65.30$ & 173 & 43.25 \\
\hline $\mathbf{3}$ & High $(>65.30)$ & 162 & 40.50 \\
\hline & & 400 & 100 \\
\hline & & Mean $=62.18$ STD $=7.35$ \\
\hline
\end{tabular}

Table.2 Perception and acceptance of farmers towards different dimensions of IT enabled farm advisory services $n=400$

\begin{tabular}{|c|l|c|}
\hline SI No & \multicolumn{1}{|c|}{ Perception Dimension } & Average Index (\%) \\
\hline $\mathbf{1}$ & Comprehensiveness of content & 75.13 \\
\hline $\mathbf{2}$ & Field applicability & 83.35 \\
\hline $\mathbf{3}$ & Solution for pests and disease & 71.01 \\
\hline $\mathbf{4}$ & Timeliness & 48.71 \\
\hline $\mathbf{5}$ & Accuracy & 78.45 \\
\hline $\mathbf{6}$ & Speed & 39.36 \\
\hline $\mathbf{7}$ & Presentation of Audio Visual Content & 72.43 \\
\hline $\mathbf{8}$ & User Friendly Device & 55.06 \\
\hline $\mathbf{9}$ & Agricultural input selection & 70.58 \\
\hline $\mathbf{1 0}$ & Market Assistance & 44.50 \\
\hline $\mathbf{1 1}$ & Follow up support/assistance & 59.10 \\
\hline & Overall Index & $\mathbf{6 3 . 4 3}$ \\
\hline
\end{tabular}


Table.3 Distribution of farmers based on different dimensions of perception and acceptance about IT enabled farm advisory services $n=400$

\begin{tabular}{|c|c|c|c|}
\hline & \multirow{2}{*}{ Categories of Dimensions } & \multicolumn{2}{|c|}{ Distribution } \\
\hline & & Frequency & $\%$ \\
\hline \multirow[t]{5}{*}{$\mathbf{1}$} & \multicolumn{3}{|l|}{ Comprehensiveness of content } \\
\hline & Low $(<68)$ & 78 & 19.50 \\
\hline & Medium (68-82) & 171 & 42.75 \\
\hline & High $(>82)$ & 151 & 37.75 \\
\hline & \multicolumn{3}{|l|}{ Mean $=75.00 \mathrm{STD}=16.00$} \\
\hline \multirow[t]{5}{*}{2} & \multicolumn{3}{|l|}{ Field Applicability } \\
\hline & Low $(<77.31)$ & 105 & 26.25 \\
\hline & Medium (77.31-90.00) & 141 & 35.50 \\
\hline & High $(>90.00)$ & 154 & 38.50 \\
\hline & Mean $=83.35$ STD $=14.23$ & & \\
\hline \multirow[t]{5}{*}{3} & \multicolumn{3}{|l|}{ Solution for pests and disease } \\
\hline & Low $(<62.65)$ & 54 & 13.50 \\
\hline & Medium (62.65-74.50) & 188 & 47.00 \\
\hline & $\operatorname{High}(>74.50)$ & 158 & 39.50 \\
\hline & Mean $=71.01 \mathrm{STD}=8.34$ & & \\
\hline \multirow[t]{5}{*}{4} & \multicolumn{3}{|l|}{ Timeliness } \\
\hline & Low $(<44.71)$ & 74 & 18.50 \\
\hline & Medium (44.71-52.71) & 227 & 56.75 \\
\hline & High $(>52.71)$ & 99 & 24.75 \\
\hline & Mean $=48.71 \quad$ STD $=9.43$ & & \\
\hline \multirow[t]{5}{*}{5} & \multicolumn{3}{|l|}{ Accuracy } \\
\hline & Low $(<70.00)$ & 71 & 17.75 \\
\hline & Medium (70-87.30) & 184 & 46.00 \\
\hline & High $(>87.30)$ & 145 & 36.25 \\
\hline & Mean $=78.45 \quad \mathrm{STD}=20.84$ & & \\
\hline \multirow[t]{5}{*}{6} & \multicolumn{3}{|l|}{ Speed } \\
\hline & Low $(<37)$ & 179 & 44.75 \\
\hline & Medium $(37-42.160)$ & 94 & 23.50 \\
\hline & High $(>42.16)$ & 127 & 31.75 \\
\hline & Mean $=39.36 \mathrm{STD}=6.64$ & & \\
\hline \multirow[t]{5}{*}{7} & \multicolumn{3}{|l|}{ Presentation of Audio Visual Content } \\
\hline & Low $(<67.43)$ & 71 & 17.75 \\
\hline & Medium (67.43-72.43) & 92 & 23.00 \\
\hline & High $(>72.43)$ & 237 & 59.25 \\
\hline & Mean $=72.43 \quad \mathrm{STD}=11.75$ & & \\
\hline \multirow[t]{5}{*}{8} & \multicolumn{3}{|l|}{ User Friendly Device } \\
\hline & Low $(<44.31)$ & 86 & 21.50 \\
\hline & Medium (44.31-60) & 215 & 53.75 \\
\hline & High $(>60)$ & 99 & 24.75 \\
\hline & Mean $=55.06 \quad \mathrm{STD}=11.11$ & & \\
\hline 9 & Agricultural Input Selection & & \\
\hline & $\operatorname{Low}(<66)$ & 119 & 29.75 \\
\hline & Medium(66-75.04) & 111 & 27.75 \\
\hline & $\operatorname{High}(>75.04)$ & 170 & 42.50 \\
\hline & Mean $=70.58 \quad \mathrm{STD}=10.53$ & & \\
\hline 10 & Market Assistance & & \\
\hline & Low $(<37.644)$ & 142 & 35.50 \\
\hline & Medium(37.644-51.35) & 74 & 18.50 \\
\hline & High $(>51.35)$ & 150 & 37.50 \\
\hline & Mean $=44.5 \mathrm{STD}=16.13$ & & \\
\hline 11 & Follow up support/assistance & & \\
\hline & Low $(<57.88)$ & 36 & 09.00 \\
\hline & Medium (57.88-60.31) & 364 & 91.00 \\
\hline & High $(>60.31)$ & 0 & 0.00 \\
\hline & Mean $=59.10 \mathrm{STD}=2.86$ & & \\
\hline
\end{tabular}


The study conducted by Admane (2014) also revealed that 65 per cent of farmers were satisfied with the e-Chaupal services. Hence, it can be concluded that the above components of dimensions of information technology (IT) play a very important role in perception which may lead to adoption.

\section{Distribution of farmers based on different dimensions of perception and acceptance about IT enabled farm advisory services}

The results of the table 3 gives the detailed explanation of distribution of farmers according to different dimensions of perception and acceptance. It was seen that 42.75 per cent of the farmers were in medium category of perception and acceptance, 37.75 per cent were in high category of perception and acceptance and only 19.50 per cent were in low category of perception and acceptance with respect to comprehensiveness of content. In dimension- field applicability, a little more than one third ( 38.50 per cent) of the farmers were in high category of perception and acceptance, 35.50 per cent were in medium category of perception and acceptance and 19.50 per cent were in low category of perception and acceptance. The farmers when questioned about the solution they got for incidence of pests and disease on the scale revealed that 47.00 per cent belonged to medium category of perception and acceptance, 39.50 per cent were in high category of perception and acceptance and 13.50 per cent were in low category of perception and acceptance. The tablet used for information technology based farm advisory services was supposed to give real time solution to the problems so items were also on the perception of timeliness and it was found that more than half of the farmers were in medium category of perception and acceptance with respect to timeliness and 24.75 per cent had high and 18.50 per cent were in low category of perception and acceptance, respectively. With respect to accuracy 46 per cent of the farmers were in medium category of perception and acceptance. 36.50 per cent of the farmers were in high category of perception and acceptance and only 17.75 per cent of farmers were in low category of perception and acceptance, similarly in case of speed nearly half of the respondents i.e. 44.75per cent were in low category of perception and acceptance, followed by 31.75 per cent who belonged to high category of perception and acceptance and 23.50 per cent were in medium category of perception and acceptance. Audio visual content is important part of any IT based device hence, we can see that about 60 per cent of the farmers were in high category of perception and acceptance and 23 per cent belonged to medium category of perception and acceptance and 17.75 per cent belonged to low category of perception and acceptance. Fifty three point seven five per cent of farmers were in high category of user friendliness, about a quarter (24.75per cent) of the farmers were in high category of perception and acceptance and 21.50 per cent were in low category of perception and acceptance. In case of agricultural input selection 42.50 per cent of the farmers were in high category of perception and acceptance, 29.75 per cent of the farmers were in low category of perception and acceptance and 27.75 per cent of the farmers belonged to medium category of perception and acceptance. With regard to market assistance almost equal per cent of the farmers i.e. 37.50 and 35.50 were in high and medium category of perception and acceptance and 18.50 per cent belonged to low category of perception and acceptance. On follow up assistance 91 per cent were in medium category of perception and acceptance and only 9 per cent belonged to low category of perception and acceptance and no farmer was in high category of perception. It was observed in table 3 more farmers had medium level of 
perception with respect to dimensions like comprehensiveness of content, solutions for pest \& disease, timeliness, accuracy, user friendly device and follow up support \& assistance. The main feature of the programme includes specific technologies to the area and pest and disease surveillance. It was supported by photos \& videos apart from diagnosing problems and solution for pest and disease. The Raitha Mitras visited the farmer's field regularly to see the progress of the crop from sowing to harvesting and provided needful information. The printed advice was provided to the farmers in their fields on the spot. So it was easier for famers to identify with the farm advisory service which provided instant solution to their problems. These may be the possible reason for such type of result.

The agricultural input selection is an important aspect of farming which highly affects the crop yield and decision making. So it was seen that more number of the farmers had high perception about agricultural input selection.

About 60 per cent of the farmers were in high perception about perception category with respect to content. Which means that when there is an interface (TAB loaded with photos and videos) between farmers and extension agents. It helps the farmers to perceive the problems visually and identify the solutions. As mentioned earlier, the photos and videos on crop varieties as well as operations was included in the programme.

However, more number of farmers were under the category of low perception on speed which means that the connectivity in the villages need to be strengthened as expressed by the farmers. The results clearly reveal that connectivity is one of the pre-requisite for successful use of IT enabled farm advisory services. Ganesan et. al. (2013) conducted a study on use of Mobile Multimedia Agricultural Advisory Systems (MAAS) came up with similar results Information on weather factors like temperature, rainfall and humidity was perceived most appropriate by more number of farmers and majority felt that information regarding the best packages of practices for various crops cultivated in the area, particularly the crops being chosen in the project were most appropriate. This information assisted the farmers to opt for more appropriate technology including choices of variety, pesticide and fertilizers etc. Hence, the inference can be drawn IT enabled farm advisory service can effectively bridge the gap between research and farmers fields.

\section{References}

Admane, R. A., 2014, ITC's e-choupal: a marketing strategy for rural transformation - a case study of Wardha district, Maharashtra. Int. J. Mgmt Res. \& Bus. Strat, 3(1): 249- 256.

Anonymous, 2000, Policy framework for agricultural extension, Extension Division, DoA \& C, Ministry of Agriculture, Government of India, New Delhi.

Anonymous, 2018, Narendra Modi Government digital India village broadband connections,https://thewire.in/governme nt/narendra-modi-government-digitalindia-village-broadband-connections

Anonymous, 2020 , https://indiamicrofinance.com/digitalindia-project-and-agriculture/

Davis, F., 1989, Perceived usefulness, perceived ease of use, and user acceptance of information technology. MIS Quarterly, 13(3): 319340. doi:10.2307/249008

Ganesan, M., Kavitha, K., Suma, P. and Jayalakshmi, U., 2013, An exploratory 
study of mobile multimedia agriculture advisory system: Challenges and lessons from Tamil Nadu, India. The Electronic J. Info. Syst. Dev. Countries., 56 (5): 1-14.

Maraddi, G, N., Prabhuraj, A. and Hiremath, G, M., 2016, A perception analysis of stakeholders towards e- SAP tool for pest management. Paper presented In: Int. Conf. - Innovative Digital Application for Sustainable Development, Univ. Agric. Sci., Bangalore, January 5-7: 678.

Sahota, C. and Kameswari, V. L. V., 2014,
Mobile Phones for Agricultural Extension in North India. Malaysian Journal of Media Studies, 16 (1):1-14.

Xiaolan $\mathrm{Fu}$ and Shaheen Akhter, 2012, Impact of Mobile Telephone on the Quality and Speed of Agricultural Extension Services Delivery: Evidence from the Rural e- Services Project in India. In: Triennial Conference International. Association of Agricultural Economists (IAAE), 18- 24 August 2012, Foz do Iguacu, Brazil,

\section{How to cite this article:}

Rajeshwari, N. and Dolli, S. S. 2021. Perception and Acceptance of Information Technology (IT) Enabled Farm Advisory Service by Farmers of Navalgund Taluka of Karnataka. Int.J.Curr.Microbiol.App.Sci. 10(01): 2456-2464. doi: https://doi.org/10.20546/ijcmas.2021.1001.284 